\title{
Effect of storage solutions on microhardness of crown enamel and dentin
}

\author{
Berdan Aydın ${ }^{1}$, Tijen Pamir ${ }^{2}$, Aysun Baltaci ${ }^{3}$, Mehmet N. Orman ${ }^{4}$, Tugba Turk ${ }^{5}$
}

Correspondence: Dr. Berdan Aydın

Email: berdanaydin@gmail.com

\begin{abstract}
'Department of Restorative Dentistry, University of Illinois at Chicago College of Dentistry, USA

${ }^{2}$ Department of Restorative Dentistry, Ege University, Turkiye,

${ }^{3}$ Department of Mechanical Engineering, Ege University, Turkiye,

${ }^{4}$ Department of Biostatistics, Ege University, Turkiye,

${ }^{5}$ Department of Endodontics, Ege University, Turkiye
\end{abstract}

\section{ABSTRACT}

Objective: The aim of this study was to determine alterations in microhardness of crown dentin and enamel, after 2 and 12-month storage in de-ionized water, 0.2\% glutaraldehyde, Hanks' Balanced Salt Solution (HBSS), 0.1\% sodium hypochlorite $(\mathrm{NaOCl})$ or $0.1 \%$ thymol. Materials and Methods: Freshly extracted, nonsterile 60 intact human premolars were distributed to five groups. Six teeth from each group were evaluated after two, and other six teeth were evaluated after 12 months storage. After grinding and polishing of teeth, Vickers hardness was evaluated with making indentations on enamel and dentin, using a pyramid diamond indenter tip exerting $100 \mathrm{~g}$ load for $15 \mathrm{~s}$. Results: After 2 months storage in solutions, range of the hardness values (HV) of enamel and dentin were in between 315-357 and 64-67, respectively. However, 12 months storage of the teeth resulted in a statistically significant decrease in microhardness when compared to microhardness of teeth stored for 2 months $(P=0.001)$. Although the differences were not significant regarding solutions, all solutions decreased the microhardness both in enamel and dentin $(P>0.05)$. However, decrease in microhardness was relatively less in de-ionized water and thymol solutions while glutaraldehyde decreased microhardness the most: $63 \%$ for enamel and $53 \%$ for dentin. Conclusions: Microhardness of enamel and dentin was in an acceptable range when teeth were stored for 2 months in de-ionized water, glutaraldehyde, $\mathrm{HBSS}, \mathrm{NaOCl}$ or in thymol; thus, teeth kept up to 2 months in these solutions can be used for mechanical in vitro tests. However, 12 months storage significantly decreased the microhardness of enamel and dentin.

Key words: Dentin, enamel, microhardness, storage of teeth, storage solutions

\section{INTRODUCTION}

Microhardness is the gold standard parameter to observe alterations of mechanical properties in mineralized tissues and a good predictor of the other important mechanical properties such as Young's modulus and yield stress. ${ }^{[1]}$ Nanoindentation technique, which is the latest technology in hardness measurement, has been developed to investigate surfaces at smaller scales, especially for thin surface coatings and films. ${ }^{[2]}$ Even though nanoindentation studies have been published widely in the last decade, ${ }^{[3-5]}$ only the thin superficial layer of tissues can be examined. The conventional microhardness assessment is done by either Vickers or Knoop tests. While Knoop indenter is able to reveal deformations 20 $\mu \mathrm{m}$ in length, as small as $5 \mu \mathrm{m}$ area in diameter can be measured by Vickers indenter; in other words, Vickers indenter is more sensitive to plastic deformations. ${ }^{[6]}$

Extracted human teeth have a crucial importance as a fundamental material in in vitro dental studies. Following extraction, their maintenance immediately requires $100 \%$ humidity, ${ }^{[7]}$ and the easiest storage is immersing the teeth into aqueous solutions, such as de-ionized water, thymol, and Hanks' Balanced Salt

How to cite this article: Aydin B, Pamir T, Baltaci A, Orman MN, Turk T. Effect of storage solutions on microhardness of crown enamel and dentin. Eur J Dent 2015;9:262-6. 
Solution (HBSS) ${ }^{[3,8]}$ Nonetheless, storage conditions of extracted teeth can alter the mechanical properties of dental tissues, ${ }^{[9]}$ which can greatly affect the result of the mechanical tests during experimental processes. It is known that mechanical properties of dentin and enamel are dependent to their mineral content, ${ }^{[10]}$ and aqueous solutions can result in mineral leaching while preserving the hydration of dental hard tissues. ${ }^{[8]}$

In this study, the null hypothesis was tested that the microhardness of nonsterile intact teeth does not significantly change if teeth are kept for 12 months in a jar filled with de-ionized water, $0.2 \%$ glutaraldehyde, HBSS, $0.1 \%$ sodium hypochlorite $(\mathrm{NaOCl})$ or $0.1 \%$ thymol at room temperature.

\section{MATERIALS AND METHODS}

Caries free, permanent premolars were extracted for periodontological purposes after the approval of the Ethics Committee. Teeth with fully developed root apices were included in the present study. After calculus and soft tissue removal by curettes, 12 nonsterile teeth were immediately put into one of the following storage solutions: De-ionized water $(\mathrm{pH} \sim 6.5), 0.2 \%$ glutaraldehyde $(\mathrm{pH} \sim 4.8)$, HBSS (HBSS, with phenol red, with calcium and magnesium, $\mathrm{pH} \sim 7.5$, Sigma-Aldrich Corporation, St. Louis, MO, USA), $0.1 \% \mathrm{NaOCl}(\mathrm{pH} \sim 10)$, and $0.1 \%$ thymol ( $\mathrm{pH} \sim 9.1$ ). Only thymol solution, $0.1 \%$ was prepared in our laboratory.

Solutions were not replenished during the 12 months storage, which limits the dissolution of the inorganic fraction of teeth. ${ }^{[1,12]} \mathrm{Six}$ teeth from each group were taken out of the storage solution at the $2^{\text {nd }}$ month of the storage, and the other six teeth were taken out at the $12^{\text {th }}$ month. Teeth with the vestibular surfaces facing up were horizontally embedded in polyester resin. To prepare a flat surface which exposes enamel and dentin together, teeth crowns were ground $2 \mathrm{~mm}$ on their vestibular surface using 180, 220, 320, 500, 800, 1000, 1200 grit silicon carbide papers under copious water-cooling, followed by polishing with $0.05 \mu \mathrm{m}$ alumina slurry using a low-speed metallurgical polisher.

After transferring teeth to the Vickers Hardness Testing Machine (Buehler, Lake Bluff, IL, USA) six indentations on enamel and six indentations on dentin were done by a pyramid diamond indenter tip with $100 \mathrm{~g}$ load for $15 \mathrm{~s}$. On enamel and dentin, the indentations were started $200 \mu \mathrm{m}$ away from dentino-enamel junction and made toward the coronal surface on enamel and towards apical end on dentin, with keeping approximately $200 \mu \mathrm{m}$ distance between the indentations.

Means of the hardness values (HV) for enamel and dentin were separately calculated per sample, and data was processed using SPSS 15.0 (SPSS, Inc., Chicago, IL, USA). First, normalization of the data was evaluated, and statistically homogenous data distribution was verified using one-sample Kolmogorov-Smirnov test, and two-way ANOVA was used.

\section{RESULTS}

Vickers hardness value was calculated using the formula: $\mathrm{HV}=1.854 \times \mathrm{F} / \mathrm{d}^{2}$. Applied load is "F (kgf)," and right after the indentation, a diagonal length of the pyramid-shaped impression on the substrate is "d (mm)."

Mean HV of enamel and dentin are shown in Table 1. The hardness of the teeth stored in different solutions was compared, no statistical differences were found depending either on the solution used or the periods of storage $(P>0.05)$ [Figure 1].

For each solution type, microhardness at the $12^{\text {th }}$ month was significantly less than that at the $2^{\text {nd }}$ month storage (two-way ANOVA, $P=0.001$ ); however, the decrease rate in microhardness was similar in all groups [Table 2].

\section{DISCUSSION}

In this study, the null hypothesis was rejected since the microhardness of nonsterile intact teeth significantly changes if teeth are kept for 12 months in de-ionized

\begin{tabular}{|c|c|c|c|c|}
\hline & \multirow[t]{2}{*}{ Month } & \multicolumn{2}{|c|}{$\begin{array}{c}\text { Mean } \pm S D \\
\text { HV }\end{array}$} & \multirow[t]{2}{*}{ Sample (n) } \\
\hline & & Enamel & Dentin & \\
\hline \multirow[t]{2}{*}{ De-ionized water } & 2 & $335 \pm 24^{a}$ & $66 \pm 6^{v}$ & 6 \\
\hline & 12 & $177 \pm 55^{\mathrm{a}}$ & $44 \pm 10^{v}$ & 6 \\
\hline \multirow[t]{2}{*}{ Glutaraldehyde } & 2 & $357 \pm 22^{b}$ & $70 \pm 6^{w}$ & 6 \\
\hline & 12 & $132 \pm 21^{b}$ & $33 \pm 5^{w}$ & 6 \\
\hline \multirow[t]{2}{*}{ HBSS } & 2 & $316 \pm 41^{c}$ & $64 \pm 4^{x}$ & 6 \\
\hline & 12 & $151 \pm 19^{c}$ & $34 \pm 9^{x}$ & 6 \\
\hline \multirow[t]{2}{*}{$\mathrm{NaOCl}$} & 2 & $315 \pm 31^{d}$ & $67 \pm 7^{y}$ & 6 \\
\hline & 12 & $153 \pm 19^{d}$ & $38 \pm 6^{y}$ & 6 \\
\hline \multirow[t]{2}{*}{ Thymol } & 2 & $327 \pm 41^{\mathrm{e}}$ & $66 \pm 4^{z}$ & 6 \\
\hline & 12 & $178 \pm 66^{e}$ & $38 \pm 7^{z}$ & 6 \\
\hline
\end{tabular}

SD: Standard deviation, HV: Hardness value, HBSS: Hanks' Balanced Salt Solution, $\mathrm{NaOCl}$ : Sodium hypochlorite, There was no significant statistical difference between the groups marked with the same letters 


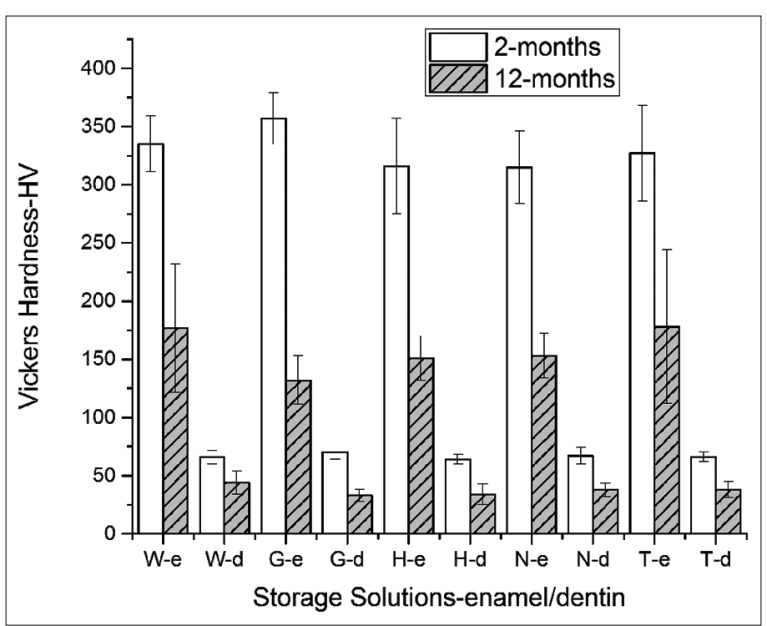

Figure 1: Microhardness of enamel and dentin at the $2^{\text {nd }}$ and the $12^{\text {th }}$ month. W: Deionized Water, G: Glutaraldehyde - 0.2\%, H: Hanks' Balanced Salt Solution, N: NaOCl - 0.1\%, T: Thymol - 0.1\%

\begin{tabular}{|c|c|c|}
\hline & Enamel (\%) & Dentin (\%) \\
\hline De-ionized water & 47 & 35 \\
\hline Glutaraldehyde & 63 & 53 \\
\hline HBSS & 52 & 47 \\
\hline $\mathrm{NaOCl}$ & 51 & 43 \\
\hline Thymol & 45 & 42 \\
\hline
\end{tabular}

water, $0.2 \%$ glutaraldehyde, HBSS, $0.1 \% \mathrm{NaOCl}$ or $0.1 \%$ thymol at room temperature. Results showed all storage solutions decrease the hardness of the teeth in a similar fashion.

However, results also showed that storing nonsterile intact teeth for 2 months in these solutions with mentioned concentrations maintain the microhardness of teeth.

After extraction, solution where nonsterile teeth are collected is not changed due to hygienic concerns in a clinic dedicated to patient-care. Hence, teeth sometimes are kept in the storage solutions for months until a sufficient number of teeth are collected for an experiment. It is known that sterilization of teeth can only be achieved by the gamma irradiation; other methods such as ethylene oxide, dry heat, and autoclave cause significant changes in physical and chemical composition of dental tissues. ${ }^{[13]}$ Gamma sterilization facilities in medical and dental hospitals are not common throughout the world. Thus, storing extracted teeth in an antimicrobial solution is the most preferred method where access to gamma irradiation is limited.
Antimicrobial agents in which extracted teeth are stored can penetrate into dental tissues and may cause undesired effects during experimental studies. To avoid that, a jar filled with de-ionized water is generally preferred during the collection of teeth. Regarding replenishment of the storage solutions, Baillif et al. ${ }^{[11]}$ showed that increase in inorganic material leaching with more frequent replenishment of saline solution. In the present study, storage solutions were not replenished for 12 months to minimize the dissolution of the inorganic fraction of teeth. Irrelevant to the solution used, average Vickers micro HV obtained after 2 months of storage (changing in between 315-357 for enamel and 64-67 for dentin) were in agreement with the previous studies' results. ${ }^{[14,15]}$

In a study, even after a single day of storage in de-ionized water, a $25 \%$ decrease in the hardness of both enamel and dentin was demonstrated; however, exposed tooth tissues were introduced to storage solutions in mentioned study. ${ }^{[3]}$ In present study, even though the teeth stored in solutions were intact, a microhardness decrease of $47-63 \%$ in enamel and $35-53 \%$ in dentin was found between the 2 and 12 months of storage [Table 2].

Nolong-term study wasfound in the literature showing hardness change of the teeth by storage solutions. Thus, a most relevant, but a short-term study done by Habelitz et al. ${ }^{[3]}$ was referred. They observed a 77\% decrease in hardness of enamel and a $63 \%$ decrease for dentin after storing sterile teeth slices in de-ionized water for 2 weeks. However, their results were based on nanoindentation measurements. Hence, to compare their hardness results with the results of the present study, their hardness unit (GPa) was converted to Vickers HV. To convert GPa to HV, GPa hardness value is divided by 0.009807 . According to the results of this calculation, it is concluded that Habelitz et al..$^{[3]}$ detected very low HV after storage; approximately $82 \mathrm{HV}$ for enamel and $40 \mathrm{HV}$ for dentin. However, in this study, hardness of enamel was $177 \mathrm{HV}$ at the end of the 1-year storage in de-ionized water [Table 1], in spite of the fact that nanoindentation hardness is about $10-30 \%$ greater than the microhardness. ${ }^{[16,17]}$ This catastrophic hardness loss observed by Habelitz et al. ${ }^{[3]}$ as quickly as 2 weeks, can be explained by the submerging of the exposed tissue slices into the storage solutions. It is known that hardness of the outer enamel layer is much greater than the layers underneath, ${ }^{[18]}$ and this layer can limit the penetration of the storage solutions when compared to the exposed dentin. Therefore, solutions can show 
their dissolution effect earlier on enamel and dentin if submerged samples were sectioned. In addition, microhardness test results obtained from tooth slices can be misleading due to different thickness of tissues on each slice. It is known that microhardness is greater if the tissue is thicker. ${ }^{[10,19]}$

Outer tissues of teeth crown were evaluated $200 \mu \mathrm{m}$ intervals with using six indentations in the present study, and $\sim 1.2 \mathrm{~mm}$ superficial layer of dentin was scanned. However, enamel was thoroughly examined because it can only be as thick as $1.5 \mathrm{~mm}$ at the cusp of premolar teeth. ${ }^{[20]}$ Thymol solutions at $0.1 \%$ concentration have been widely used to store teeth prior to mechanical testing. The same concentration of thymol and $\mathrm{NaOCl}$ solutions was compared in this study, and no significant difference was found in their effect on microhardness of teeth. $\mathrm{NaOCl}$ solutions at an efficient concentration (2.5\%) for root canal irrigation significantly decrease dentin hardness in a very short duration such as $15 \mathrm{~min} \cdot{ }^{[21]}$ However, a low concentration of $\mathrm{NaOCl}$ solution such as $0.1 \%$ was not more effective than de-ionized water in the weakening of hard tissues.

Wemes and Arends ${ }^{[15]}$ reported that $2 \%$ glutaraldehyde resulted in a remarkable decrease $(15 \%)$ in the hardness of bovine dentin after $20 \mathrm{~min}$; however, a reverse effect occurred after a relatively long period of storage: $15 \%$ hardening was observed compared to sound dentin after 2 days of storage. Ten times diluted concentration of glutaraldehyde $(0.2 \%)$ was used in this study, and even though there were no statistical differences between the groups, microhardness of teeth stored in glutaraldehyde $(0.2 \%)$ were larger than that of other groups at $2^{\text {nd }}$ month. As mentioned in the conclusion of the study of Wemes and Arends, ${ }^{[15]}$ hardening of dentin can be attributed to the cross-linking of the collagen by glutaraldehyde. The mechanism preventing the dissolution of the minerals in dental hard tissues can be explained by the limited transport of the ions such as calcium and phosphate out of the cross-linked organic material. ${ }^{[22]}$

In a previous study, it was shown that $2 \%$ glutardialdehyde can be able to penetrate 2-mm dentin slabs approximately $200 \mu \mathrm{m}$ in a week. ${ }^{[22]}$ Caries-free, intact teeth were used in the present study; so, penetration of the glutaraldehyde solution most likely would occur via the apical foramen, or cementoenamel junction where dentin tissue may directly contact and absorb the solution. Even though the penetration rate in enamel is not known, glutaraldehyde solution may completely penetrate intact teeth in 12 months. At the end of 1-year of storage, decrease in hardness was $63 \%$ in enamel versus $53 \%$ decrease in dentin. Since the inorganic fraction of enamel $(\sim 85 \%)$ is greater than that of dentin $(\sim 50 \%),{ }^{[23]}$ a larger decrease in hardness was observed in enamel. Briefly, storing teeth for 12 months in glutaraldehyde $(0.2 \%)$ resulted in a dramatic decrease in hardness compared to other storage solutions [Table 2] in the present study. This observation may be explained by the early demineralization of the tissues by the acidic environment ( $\mathrm{pH} \sim 4.8$ for $0.2 \%$ glutaraldehyde) followed by long-term aqueous degradation of enamel and dentin, since glutaraldehyde concentration may not be high enough to contribute cross-linkages in the collagen fibrils.

Hanks' Balanced Salt Solution with highly concentrated $\mathrm{Ca}, \mathrm{Mg}, \mathrm{Na}, \mathrm{PO}_{4}$, and $\mathrm{Cl}$ ions that do not dissolve calcium phosphate composition of teeth and did not change the hardness of teeth in 2 weeks.

It was previously shown that HBSS with highly concentrated $\mathrm{Ca}, \mathrm{Mg}, \mathrm{Na}, \mathrm{PO}_{4^{\prime}}$ and $\mathrm{Cl}$ ions does not dissolve calcium phosphate composition of teeth and does not change the hardness of teeth in 2 weeks. ${ }^{[3]}$ In this study, a similar HBSS solution with ions was used; however, hardness of teeth was no different than the teeth in other storage solutions including $0.1 \% \mathrm{NaOCl}$ and de-ionized water. This result can be attributed to the storage periods in HBSS, of which constant ion concentration may not be able to compensate the leaching of teeth beyond 2 weeks in the present study.

\section{CONCLUSION}

The hardness of teeth stored for 2 months in de-ionized water, $0.2 \%$ glutaraldehyde, $\mathrm{HBSS}, 0.1 \% \mathrm{NaOCl}$ or in $0.1 \%$ thymol was acceptable for in vitro tests. However, neither diluted antimicrobial solutions nor HBSS prevented a decrease in microhardness of nonsterile teeth after 12 months storage. Hence, to test the applicability of a storage solution, long-term studies evaluating changes in mechanical properties of teeth are necessary.

\section{ACKNOWLEDGMENTS}

Authors would like to thank to Prof. Dr. Bilge Hakan Şen, Dr. Özge Gülmez.

\section{REFERENCES}

1. Currey JD, Brear K. Hardness, young's modulus and yield stress in mammalian mineralized tissues. J Mater Sci Mater Med 1990;1:14-20. 


\section{Aydın, et al:: Storage solutions and microhardness of teeth crown}

2. Stachowiak GW, Batchelor AW, Stachowiak GB. Characterization of test specimens. In: Dowson D, editor. Experimental Methods in Tribology. $1^{\text {st }}$ ed. Oxford: Elsevier; 2004. p. 115-50.

3. Habelitz S, Marshall GW Jr, Balooch M, Marshall SJ. Nanoindentation and storage of teeth. J Biomech 2002;35:995-8.

4. Toparli M, Koksal NS. Hardness and yield strength of dentin from simulated nano-indentation tests. Comput Methods Programs Biomed 2005;77:253-7.

5. Bedran-Russo AK, Pashley DH, Agee K, Drummond JL, Miescke KJ. Changes in stiffness of demineralized dentin following application of collagen crosslinkers. J Biomed Mater Res B Appl Biomater 2008;86:330-4.

6. White SN, Paine ML, Ngan AY, Miklus VG, Luo W, Wang H, et al. Ectopic expression of dentin sialoprotein during amelogenesis hardens bulk enamel. J Biol Chem 2007;282:5340-5.

7. Kishen A, Asundi A. Experimental investigation on the role of water in the mechanical behavior of structural dentine. J Biomed Mater Res A 2005;73:192-200.

8. Strawn SE, White JM, Marshall GW, Gee L, Goodis HE, Marshall SJ. Spectroscopic changes in human dentine exposed to various storage solutions - short term. J Dent 1996;24:417-23.

9. Muhleman HR. Storage medium and enamel hardness. Helv Odontol Acta 1964;8:112-7.

10. Tesch W, Eidelman N, Roschger P, Goldenberg F, Klaushofer K, Fratzl P. Graded microstructure and mechanical properties of human crown dentin. Calcif Tissue Int 2001;69:147-57.

11. Baillif P, Chouikhi B, Barbanson L, Touray JC. Dissolution kinetics of glass fibres in saline solution: In vitro persistence of a sparingly soluble aluminium-rich leached layer. J Mater Sci 1995;30:5691-9.

12. Kitasako Y, Burrow MF, Nikaido T, Tagami J. The influence of storage solution on dentin bond durability of resin cement. Dent Mater 2000;16:1-6.

13. White JM, Goodis HE, Marshall SI, Marshall GW. Sterilization of teeth by gamma radiation. J Dent Res 1994;73:1560-7.

14. Craig RG, Peyton FA. The micro-hardness of enamel and dentin. J Dent Res 1958;37:661-8.
15. Wemes JC, Arends J. The hardness of bovine dentine after glutaraldehyde treatment. Oral Surg Oral Med Oral Pathol 1984;58:722-4.

16. Qian L, Li M, Zhou Z, Yang H, Shi X. Comparison of nano-indentation hardness to microhardness. Surf Coat Technol 2005;195:264-71.

17. Bao T, Morrison PW, Woyczynski W. AFM Nanoindentation as a method to determine microhardness of hard thin films. Mater Res Soc Symp Proc 1998;517:395-402.

18. He LH, Swain MV. Enamel - A functionally graded natural coating. J Dent 2009;37:596-603.

19. Alrabii SA, Zumot LY. Chip thickness and microhardness prediction models during turning of medium carbon steel. J Appl Math 2007;2:1-12.

20. Bozkurt FO, Tagtekin DA, Hayran O, Stookey GK, Yanikoglu FC. Accuracy of ultrasound measurement of progressive change in occlusal enamel thickness. Oral Surg Oral Med Oral Pathol Oral Radiol Endod 2005;99:101-5.

21. Ari H, Erdemir A, Belli S. Evaluation of the effect of endodontic irrigation solutions on the microhardness and the roughness of root canal dentin. J Endod 2004;30:792-5.

22. Arends J, Ogaard B, Ruben J, Wemes J, Rölla G. Influence of glutardialdehyde on dentin demineralization in vitro and in vivo. Scand J Dent Res 1989;97:297-300.

23. Ten Cate AR. Oral Histology: Development, Structure, and Function. $4^{\text {th }}$ ed. St. Louis: Mosby; 1994. p. 141-90.

\begin{tabular}{|l|l|}
\hline \multicolumn{2}{|c|}{ Access this article online } \\
\hline Quick Response Code: & Website: \\
& www.eurjdent.com \\
\cline { 3 - 4 } &
\end{tabular}

